\title{
LA IMAGEN EN EL MUNDO ANDINO. DISCOS GIRATORIOS PROTOPASTOS ${ }^{1}$
}

\author{
DIANA CRISTINA CÓRDOBA CELY \\ Antropóloga, Universidad de los Andes. \\ Magister en Etnoliteratura, Universidad de Nariño.
}

El runa escucha la tierra, el paisaje y el cielo;

él siente la realidad mediante su corazón (Estermann, 1998)

\section{RESUMEN}

Este artículo se propone reflexionar sobre la adquisición del conocimiento a través de la experiencia primaria, la de los sentidos, y como eso se evidencia en la imagen prehispánica andina, específicamente en la de los discos giratorios protopastos. Para conseguir lo anterior se reflexiona sobre algunas discusiones en torno a la imagen y lo visual, más que todo en el contexto colonial y, finalmente, se muestra como los artefactos culturales en mención presentan, celebran, recrean y re-presentan el conocimiento de su etnia, logrando que su retórica visual, su mito trascienda en las artesanías y arte contemporáneo.

Así, este texto acude a los resultados de investigación del proyecto interpretación arqueológica y visual de los discos giratorios protopastos encontrados en Pupiales, Nariño, cuyo paradigma fue el interpretativo.

Palabras clave: artesanía contemporánea, conocimiento, Discos Giratorios Protopastos, sentidos.

\section{ABSTRACT}

This article aims to reflect on the acquisition of knowledge through primary experience, that of the senses, and how this is evidenced in the Andean prehispanic image, specifically in that of protopast rotating discs. To achieve the above, we reflect on

1. Artículo resultado de las investigaciones: Arqueología visual de los Discos Giratorios Protopastos encontrados en el cementerio de Miraflores, Pupiales, Nariño y Diseño de una Unidad Museográfica para el Museo de Historia Nariñense Juan Lorenzo Lucero, investigaciones avaladas y financiadas por el Ministerio de Cultura y la Institución Universitaria Cesmag. 
some discussions about the image and the visual, especially in the colonial context and, finally, it shows how the cultural artifacts in question present, celebrate, recreate and re-present the knowledge of their ethnicity, achieving that its visual rhetoric, its myth transcends in crafts and contemporary art.

Thus, this text goes to the research results of the archaeological and visual interpretation project of the protopast rotating discs found in Pupiales, Nariño, whose paradigm was the interpretative one.

Keywords: Knowledge, senses, Discos giratorios protopastos, contemporary crafts.

\section{INTRODUCCIÓN}

Los discos giratorios protopastos son unas "placas circulares, hechas con una aleación de oro y cobre con peso repartido y bien calibrado; su diámetro oscila entre los 15 y los 18 centímetros; con un agujero en el epicentro. Están decoradas con aspas, espirales y otros motivos geométricos, por sus dos caras" (Plazas y Echeverri, 1982, p. 2).

Estos objetos culturales elaborados por los protopastos exponen en su espacio pictográfico una sabiduría visual milenaria que ha sido transmitida y heredada a diferentes artistas de la región de Nariño- Colombia, este legado de comunicación visual ha ido trascendiendo en diferentes épocas hasta llegar a la actualidad donde se continúa reproduciendo en diversas expresiones creativas enmarcadas en lo cultural. De esa manera, las imágenes que están en estos artefactos confirman la importancia semántica que tienen pues han continuado recreando y legitimando un pensamiento visual propio.

Entonces, en este texto se acude a esas enunciaciones ancestrales que permanecen en la actualidad porque se cree que exaltan una "voluntad de representación que se afirma a sí misma” (Castro Gómez \& Mendieta, 1998, p. 19); una aseveración permanente de estas comunidades que hacen que estas iconografías se conviertan en una huella de sensibilidad particular que seguirá marcando a los grupos que viven en esta zona.

Así en este artículo se pretende, a partir de los resultados de investigación del proyecto Interpretación arqueológica y visual de los discos giratorios protopastos, reflexionar sobre la significancia que le daban los indígenas andinos a la adquisición del conocimiento a través de los sentidos, lo cual se evidencia, a nuestro parecer, en gran parte de la iconografía andina y específicamente en el caso de las imágenes de los discos giratorios protopastos.

Por ese motivo primero se redacta una sección donde se hace una breve revisión de la relación entre imagen y racionalismo en el mundo occidental y donde se muestra la primacía que adquirió la imagen particular de la palabra escrita. Eso parece contextualizar al lector en la temática.

En otra sección se reflexiona sobre el saber visual andino proporcionando ejemplos concretos de los discos giratorios protopastos en artesanías actuales de la región de Nariño y donde se puede observar que muchos de los elementos 
gráficos ancestrales trascendieron y siguen vigentes. En esa última parte se explica cómo el carácter eminentemente celebrativo que le daban los prehispánicos a estas imágenes, las cargaron de pregnancia y trascendencia, por lo que se muestran casos concretos de cómo ese saber que se ve en la iconografía de los discos giratorios protopastos se sigue dibujando más que todo en las artesanías del Departamento de Nariño (Colombia).

Por tanto, en este escrito se reflexiona en torno a algunas prácticas culturales visuales originarias del mundo prehispánico que se quedaron en el recuerdo de los grupos nariñenses andinos para habitar su contemporaneidad.

\section{METODOLOGÍA}

Este artículo es el resultado de la investigación denominada Interpretación arqueológica y visual de los discos giratorios protopastos encontrados en Pupiales, Nariño cuyo diseño metodológico se elaboró teniendo en cuenta el paradigma interpretativo, el enfoque histórico hermenéutico y el método etnográfico. La población tomada en esa investigación fueron 14 discos giratorios protopastos y la triangulación final permitió acercarse a diferentes tipos de artesanías de las cuales, en este documento solo se tomarán los murales realizados en las casas del municipio de Ipiales y Pupiales, algunas artesanías del carnaval, el mopa-mopa, logotipos empresariales, textiles y algunas graficaciones de artistas contemporáneos donde estas imágenes prehispánicas siguen siendo usadas junto a sus características específicas.
La triangulación de teorías, datos e investigadores en el proyecto mencionado, permitieron alcanzar resultados de investigación valiosos, que desde luego se tuvieron en cuenta para elaborar este artículo de reflexión.

\section{LA IMAGEN EN EL MUNDO PREHISPÁNICO Y OCCIDENTAL}

"La negación de la simultaneidad epistémica, esto es, la coexistencia en el tiempo y el espacio de diferentes formas de producir conocimientos crea un doble mecanismo ideológico. En primer lugar, al no compartir el mismo tiempo histórico y vivir en diferentes espacios geográficos, el destino de cada región es concebido como no relacionado con ningún otro. En segundo lugar, Europa/Euro-Norteamérica son pensadas como viviendo una etapa de desarrollo (cognitivo, tecnológico y social) más avanzada que el resto del mundo, con lo cual surge la idea de superioridad de la forma de vida occidental sobre todas las demás" (Castro Gómez \& Grosfoguel, 2007, p. 15).

Así, es comprensible que la concepción de la imagen y en general de lo visual heredada del racionalismo $y$ lo científico del mundo occidental, se convirtiera en la de mayor influencia en la conquista e incluso en la actualidad como lo describen Classen (1993), Córdoba, Murillo y Timarán (2013, 2015), Gruzinski (2003) pues como lo explica Castro Gómez \& Grosfoguel el conocimiento científico generado por la élite de expertos era el único aceptado como verdadero pues se consideraba que estaba en una posición neutra de observación. 
Sin embargo, en este momento es claro que

"si bien el nativo, andino o castellano, no tiene privilegios en cuanto a la verdad de la historia, sí tiene una subjetividad y una localización geohistórica (lenguas, tradiciones, mitos, leyendas, memorias) en las cuales se basa su manera de comprenderse a sí mismo, a los otros y al mundo. Y esta singularidad de experiencia y de vivencias no les puede ser negada" (Mignolo, 2007, p. 35).

Por esa razón, es significativo evidenciar que con la llegada de los españoles, la visión (y con ello la imagen y lo visual) se empieza a asumir como el único sentido válido y pertinente para acceder al conocimiento (discurso científico), así, la palabra escrita como un tipo particular de imagen se instaura en este continente, invisibilizando o rechazando de esa manera, otro tipo de imágenes diferentes a la escritura que tenían sus propios significados profundos sustentados en la relacionalidad de los sentidos y no la racionalidad.

Así, en este continente, todo lo sensorial, sobre lo cual se había construido gran parte del pensamiento prehispánico se omite, pues no responde a las modalidades de producción del conocimiento eurocéntrico es decir, que se lo considera como una forma inválida de adquirir conocimiento. Se impone entonces la racionalidad de la escritura como técnica grafocéntrica frente a las otras formas de decir propias de los andinos, se fija el decir en forma de leyes y decretos, por encima de otros decires basados en la vida experiencial. Se instaura un tipo particular de imagen basada en lo racional, sobre el uso que hacían los prehispánicos de la imagen como comunicación visual instaurada, no en lo lógico o ilógico, sino en lo corporal y, por tanto, sensorial.

Entonces la palabra escrita en Latinoamérica y en la conquista se convierte en una herramienta sin la cual no se legitima ni se sabe, pues como lo evidenció Rama (1987), en el nuevo sistema impuesto por los europeos a su arribo, el orden justifica todo, y en ese sentido la palabra escrita es considerada como la única valedera pues posee rigidez y permanencia, en oposición al habla que es asumida como insegura y precaria.

Como se viene diciendo, contrario a ese orden de la lengua escrita, a esa imagen ordenada, el mundo sensorial andino termina convirtiéndose para los españoles en un síntoma que demuestra la legalidad de esclavizar a los nativos de este continente pues hay una superioridad de ellos frente a la inferioridad de los indígenas. Eso también sucede porque como se sabe, durante el mal llamado "descubrimiento de América" el cronista oficial del rey Carlos V, Sepúlveda (1996), argumentó teológica y jurídicamente la legitimidad de esclavizar a los habitantes de América a través de las teorías de Aristóteles pues interpretó en ellas que había leyes naturales a las que se les debía dar cumplimiento como la de que "lo perfecto prima sobre lo imperfecto" (Sepúlveda, 1996; Castañeda, 2006).

En ese orden de ideas, lo perfecto considerado como lo español se toma como superior a aquello considerado como imperfecto propio de lo indí- 
gena, lo que da el convencimiento de que estos últimos deben ser "esclavos por naturaleza que pueden ser parcialmente racionales" (Castañeda, 2006). Como se puede deducir de las anteriores discusiones, se cree que en este continente no podía existir un pensamiento propio, aunque los sujetos de la herida colonial, a través del tiempo, han desvirtuado eso con la autoafirmación de un pensamiento fronterizo que se ha ido rehaciendo en medio de los procesos conflictivos producidos por visiones de mundo desemejantes.

Por lo tanto, es claro que los españoles al no entender estas otras cosmovisiones ya que no encuentran un sistema comparable con lo que ellos conocían, se tornaron incapaces de realizar traducciones culturales coherentes con las realidades indígenas, lo que los llevó a tropezarse permanentemente con ausencias, con vacíos, frente, por ejemplo, a una imagen similar a la que ellos conocían, rigurosa y aparentemente eterna como la de la grafía, que en realidad representa una visión de mundo específica de un grupo cultural concreto. En síntesis, se asume varios argumentos como auténticos, pero no se considera otros locus de enunciación y por tanto una simultaneidad epistémica.

Así, se compara y ante la falta de comprensión por enfrentarse a sistemas diferentes, se concluye sencillamente que hay ausencias, no se logra percibir que al andino prehispánico no le interesa el conocimiento abstractivo (teórico), representativo sino ahondar el mundo ceremonial, simbólico, es decir, que le importa la recreación y le incumbe la revitalización, la relacionabilidad, la complementariedad, nociones que se encuentran en la base del saber andino que se nutre de los sentidos y no del orden, la razón o la ciencia.

\section{SABER VISUAL EN LAS ARTESANÍAS CONTEMPORÁNEAS NARIÑENSES}

Enlazado con lo anterior, en esta sección se pretende mostrar cómo la imagen de los discos protopastos enmarcada en lo andino evidencia una semántica visual mítica que trascendió a través del arte y la artesanía del mopamopa, los textiles, los murales entre otros. Para eso primero se realizarán algunas reflexiones teóricas actualizadas sobre el pensamiento andino para finalmente revelar cómo la imagen de los artefactos culturales referidos y contenidos en ese pensamiento, persiste en las artesanías, consiguiendo así que se siga presentando y representando ese saber visual de manera contundente.

Entonces, lo que se propone aquí es mostrar cómo y por qué han perdurado estos relatos visuales hasta la actualidad, legitimando una semántica visual sustentada en una epistemología concreta que se insertó en la memoria visual colectiva y que actualmente continúa vigente, recreándose y siendo usada por los grupos de esta región como parte de su comunicación gráfica.

Pues bien, detengámonos en algunos aspectos del pensamiento andino para comprender mejor lo anterior, por ejemplo, en lo celebrativo, producto de un acercamiento a la realidad primordialmente emocio-afectivo $y$ 
experiencial, que partía de los sentidos, la sensación, el cuerpo.

Se puede afirmar que esa celebración fue primordial y lo sigue siendo para comprender la imagen andina pues el acercamiento que hacía el andino y en este caso el protopasto a su entorno era, como lo muestra Estermann (1998) "a través de otros modelos de acceso a la realidad como el mito, la religión, el sentimiento, la celebración y el arte" (p. 103). Por tanto, en el saber de este pueblo lo principal fue la recreación y no necesariamente la representación.

De ese modo, los actores sociales que realizaban las imágenes prehispánicas debían tener un conocimiento gráfico profundo dado por la repetición, la recreación propia de lo artesanal que hacía que se pudiera llegar incluso a la perfección matemática o geométrica sin tener conocimiento teórico de estas áreas. Así, y como se puede deducir, en el mundo prehispánico "Conocer algo significa sobre todo: realizarlo celebrativo y simbólicamente" (Estermann, 1998, p. 167), pues como se intenta continuar argumentando, el interés del runa como sujeto colectivo ${ }^{2}$ no es adquirir un saber similar al occidental que es básicamente abstractivo y teórico, sino que requiere y debe conocer la realidad a través del mito y su ceremonia grupal.

Como manifiesta Mora (2000) "En la filosofía andina, la realidad está presente en forma simbólica y no tanto en forma representativa o conceptual,

2. La subjetividad andina aunque parezca contradictorio es colectiva pues está enmarcada en una cosmovisión diferente a la occidental. así el runa andino busca la inserción mítica en el mundo, y la (re) presentación cúltica y ceremonial simbólica del mismo" $(\pi$ 5); entonces, y como insiste Estermann (1998), la realidad es una celebración, es más una recreación que una representación como ocurre en occidente.

Ahora, si bien este pensamiento no podría ser catalogado de antemano como racional, tampoco debería ser clasificado como irracional, pues de acuerdo a lo que plantea Duch (1998), el mito, que como hemos expuesto está en las imágenes de los discos giratorios protopastos, también es logos, por tanto se piensa que esa división propia de Occidente entre lo racional y sensitivo no está presente en las imágenes que estamos interpretando porque son el resultado de una comunicación basada en un filosofía diferente, donde no se necesita fraccionar o clasificar obligatoriamente, pues iría en contra de sus postulados donde todo se relaciona.

Recordemos que aún en la actualidad, algunas comunidades de quechuablantes siguen usando términos con la misma raíz como tupay y tupayuy, quechuismos cuya traducción es equivalente a verse y tocarse respectivamente, lo cual muestra que aún en esta época, en el mundo andino se siguen empleando conceptos donde los sentidos no se dividen de manera radical como en el pensamiento eurocéntrico donde el sentido de la vista y el tacto están separados e incluso jerarquizados, pues como se ha señalado, el primero fue considerado en determinadas etapas históricas como válido para la ciencia mientras que el segundo no. 
Las imágenes que encontramos hoy en las artesanías también son el producto de una relacionalidad que funciona con lógica y emoción y no por clasificaciones categóricas, pues son el producto de hábitos que parten de la experiencia de una comunidad o grupo y que favorecen la creación de modelos, si se quiere organizados, patrones que colaboran para que una imagen, aunque sea ceremonial, siga repitiéndose, pero de manera recreativa. Así, Velásquez y Ramos (2007) exponen sobre la iconografía Tayrona que la creación de un patrón es primordial pues puede volverse arquetípica y paradigmática.

Por eso, es crucial reconocer que los patrones ancestrales son dados por hábitos y prácticas que aunque son sensoriales siempre tienen en su fondo un modelo, es decir, hay un patrón gráfico en las comunidades que, paradójicamente siempre será nuevo, como ocurre con el mismo mito. De ese modo, se puede decir que es significativo reflexionar sobre la imagen andina cargada de un saber propio donde lo celebrativo, la presentación, la relacionabilidad son aspectos primordiales para entenderla de forma integral y para saber cómo se ha transformado o no el sentido de ésta en el tiempo.

\section{Imágenes prehispánicas que persisten en las artesanías contemporáneas}

La iconografía de las culturas prehispánicas expresó, en la mayoría de los casos, la complejidad del arte de las culturas ancestrales, ya que expuso de forma decisiva en artefactos y lugares comunitarios, significados que hicieron parte de su cosmovisión, favoreciendo de ese modo, que los mensajes dibujados en ellas, regresaran una y otra vez para revitalizarlas en el tiempo con absoluta destreza; es decir, que en las imágenes de los protopastos ${ }^{3}$ se puede observar una preocupación por narrar de manera gráfica, gran parte de lo que ellos consideraban primordial, sagrado y, por tanto, relacionado con el mito.

Por tanto, desde la óptica contemporánea se considera que la imagen prehispánica puede guiarnos hacia esos decires hechos memoria, puede acercarnos así, a la valoración de lo sensorial de esa época y por supuesto a las voces de estos grupos que persisten y por tanto muestran "la lucha de sus memorias sociales contra el olvido forzado" (Gnecco, 2000), pues estas imágenes cuentan relatos que se incrustaron en los grupos y continuaron vigentes como pensamiento visual fronterizo.

En el caso concreto de los discos giratorios protopastos, se puede afirmar que sus imágenes han trascendido como retórica visual en algunas artesanías gracias al artesano que las hace presentes cada vez que las elabora, así, al hacer esa práctica cultural, se representa como en muchas artesanías actuales, pero también se sigue presentando a través de la celebración y el ritual de la elaboración. De esa manera se cree que gracias a esa práctica se sigue marcando esa imagen en la memoria colectiva a través de diferentes épocas.

A continuación se mostrarán algunas artesanías contemporáneas donde en el espacio pictográfico sigue siendo

3. De acuerdo a Uribe (1989), en Nariño existen dos fases de la misma unidad cultural, los protopastos (Piartal) y los Pastos (Tuza). Si bien esta clasificación ha sido la más utilizada por los investigadores, su discusión sigue siendo profundamente polémica. 
común la utilización de simetrías, de proporciones con vacíos y llenos y en general otros usos estéticos nutridos de la mitología como imágenes de espejo, la repetición y el ritmo, la radiación, el uso de módulos, la agrupación de elementos geométricos (estrellas como el sol de los Pastos ${ }^{4}$, formas circulares y concentricidad), es decir peculiaridades proporcionadas por la visión de mundo andina.

En síntesis, se expondrá cómo en estas artesanías se encuentran similitudes ancestrales que prevalecen como la simetría de espejo, la repetición de unidades gráficas, el mismo uso de la repetición y el ritmo, pero también diferencias marcadas por otras épocas, el uso de otros tonos que no representan necesariamente la idea de la dualidad mítica, figuras modernas, etc. Para facilitar la lectura visual, se mostrará primero un disco giratorio ancestral y después un disco usado en las artesanías actuales, y en otras figuras se resaltará la iconografía ancestral en un recuadro negro en el lado derecho.

\section{a) Repetición y Ritmo}

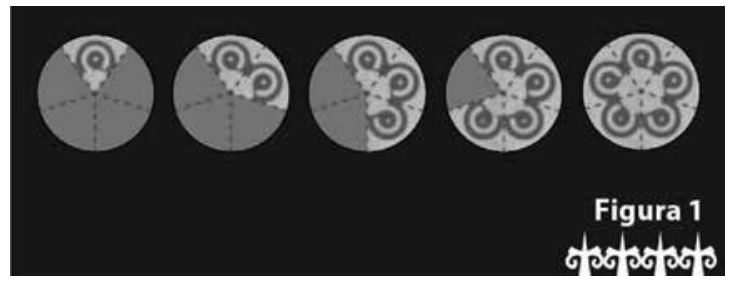

Figura 1: Disco giratorio protopasto. Repetición de módulos en un artefacto cultural prehispánico. Fuente: Propia.

4. Estrella de ocho puntas icónica y fundamental en la historia Pasto.

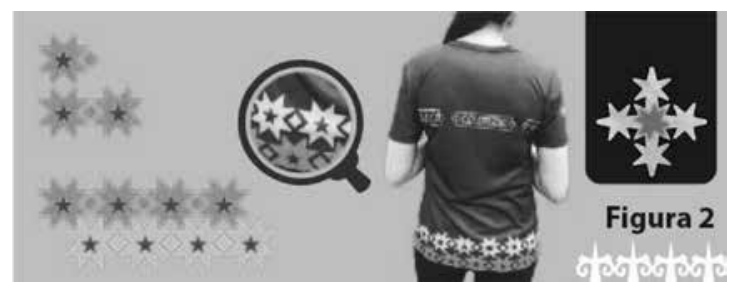

Figura 2: Imagen actual de repetición y ritmo en una artesanía donde se toma como iconografía un disco giratorio protopasto.

Fuente: Propia.

Los módulos y su repetición se han convertido en patrones gráficos ancestrales que siguen contribuyendo a la producción de la memoria social, así se demuestra en Córdoba, Murillo \& Timarán (2015) donde se expone la manera en que la repetición de éstos podría terminar siendo un ejercicio nemotécnico similar al usado en la oralidad. En ese sentido, Lepe postula que,

"La formulariedad de lo oral, que desde Walter Ong se entiende como un recurso mnemotécnico, no es solamente eso, sino que va más allá en cuanto tiene un sentido performativo ligado con el ritual, con la manera de presentar un relato como mítico, sagrado, etc., o como una manera de ejercer legitimidad en el sentido que la toma Lyotard, Bourdieu y otros" (Lepe \& Granda, 2006, p. 151).

$\mathrm{Al}$ respecto se puede afirmar que muchas de las imágenes de las artesanías presentan un desarrollo formulario, con el paso del tiempo, aunque no se modifican del todo, a su vez, y aunque parezca contradictorio cambian y ya nunca son las mismas por su performatividad, porque el ritual de su elaboración las convierte siempre en otras. 


\section{b) Simetría espejo que prevalece}

De acuerdo a Duncan (1992), la simetría de espejo muestra un efecto donde "las figuras están sistemáticamente invertidas en el doble sentido de abajo-arriba y derecha izquierda" (p. 60).

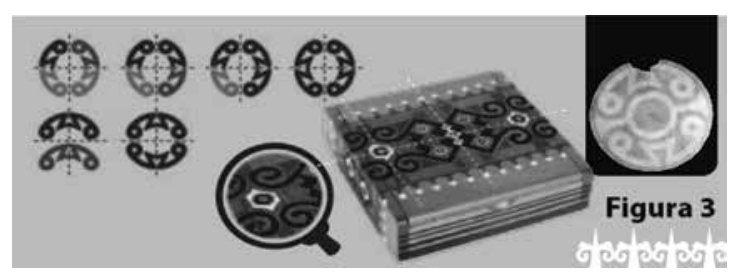

Figura 3: Simetría de espejo en un disco giratorio protopasto prehispánico y simetría de espejo en una artesanía de mopa mopa donde se usa la misma iconografía ancestral.

Fuente: Propia.

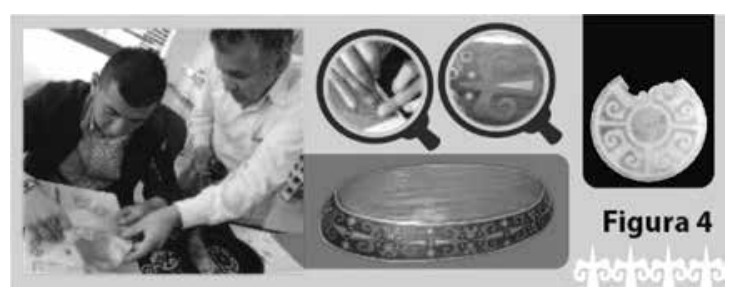

Figura 4: Simetría de espejo usando un módulo de un disco giratorio protopasto.

Fuente: Propia.

Esta simetría transferida del mito andino y su dualidad, es conocida en la teoría de grupos de las matemáticas como simetría de reflexión porque su patrón de giro es de 180 grados y, evidentemente, se continúa expresando en el espacio dibujado de estos grupos andinos, demostrando que el carácter eminentemente celebrativo que tienen estas iconografías, les ha otorgado, a través del tiempo, una pregnancia indiscutible.

En la actualidad sigue siendo común que los artesanos hagan uso de este tipo de herramientas gráficas para decorar sus artesanías, así, por poner un caso, la geometría que se observa en los discos giratorios ancestrales y en los artefactos culturales de esta época, indican que el conocimiento que se evidencia allí sigue siendo experiencial, resultado de un hábito, de una práctica permanente que les termina dando a estas imágenes, casi una exactitud matemática.

Artesanías actuales que repiten unidades gráficas o la totalidad de lo dibujado en el espacio pictográfico de los discos giratorios protopastos.

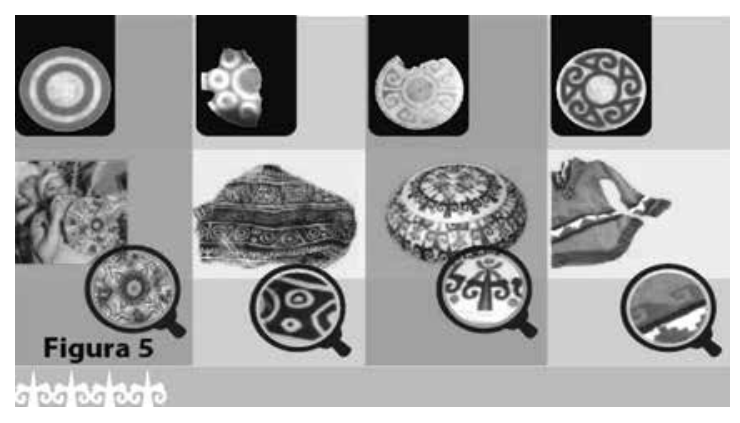

Figura 5: Artesanías donde prevalecen los discos giratorios protopastos en su totalidad o por módulos. Fuente: Propia.

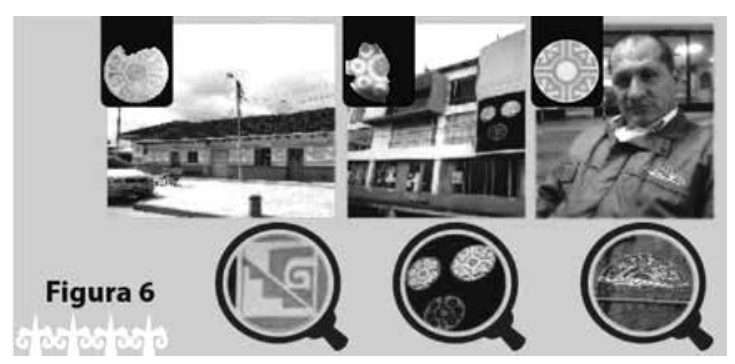

Figura 6: Discos giratorios en transporte público, casas de Ipiales y Pupiales.

Fuente: Propia.

Como se ha expuesto, las iconografías o imágenes ancestrales no siempre se continúan elaborando exactamente igual, pero eso no es un impedimento para que su retórica siga vigente. Como 
se puede observar en las figuras (2, $3,4,5,6$ ), incluso módulos o formas completas que estaban en los discos giratorios protopastos siguen siendo replicados en este momento, lo que subraya que diversas comunidades de Nariño continúan afirmando este saber basado en sensibilidades andinas particulares.

\section{CONCLUSIONES}

Para interpretar la imagen del mundo prehispánico es necesario reconocer la simultaneidad epistémica pues solo de ese modo nos podremos acercar a la imagen andina de manera ética, respetando la cosmovisión de su propia comunidad y de ese modo la forma de ver el mundo de otros grupos.

En ese mismo orden, es pertinente aceptar que la imagen eurocéntrica, y por ejemplo, la palabra escrita, fue una construcción de tiempo y lugar que se basó en la representación, el orden, entre otros aspectos propios de los discursos occidentales, por lo tanto es una construcción formulada por una elite científica determinada y bajo una lógica particular; entonces, lo visual y la imagen occidental, no pueden ser tomados como universales ni mucho menos como la plataforma semántica para comprender las imágenes nativas andinas.
En la sección de saber visual en las artesanías contemporáneas nariñenses, se puede concluir que esas producciones han adquirido un conocimiento visual por transmisión, por habilidades culturales donde sigue siendo importante la celebración, la presentación, la relacionabilidad. En esas prácticas que tienen esos artistas, se siguen repitiendo figuras por hábito, porque el pensamiento andino se nutre de lo emocio-afectivo, y la adquisición de conocimiento se da a través de los sentidos y no de lo teórico conceptual propio de la visión de mundo occidental.

Entonces, esta reflexión en torno a la imagen en el mundo andino, concretamente discos giratorios protopastos, y la importancia que tuvieron los sentidos en su elaboración, nos exigió indagar sobre cómo y porqué la imagen trascendió. Así podemos afirmar, como ya se ha dicho, que estas imágenes han permanecido hasta la actualidad gracias al valor que tuvo en el mundo antiguo adquirir el conocimiento a través de los sentidos, gracias al carácter eminentemente celebrativo de este tipo de arte que ha colaborado enormemente para que este saber visual se haya legitimado en diferentes épocas y lo siga haciendo en las artesanías presentes.

Agradecimientos a la diseñadora gráfica Paula Andrea Murillo por la elaboración de algunas de las figuras. 


\section{BIBLIOGRAFÍA}

Castañeda, F. (2006). Indicaciones sobre el Bárbaro Caníbal a partir de Aristóteles. Bogotá: Universidad de los Andes.

Castro-Gómez \& Grosfoguel, R. (Edit) (2007). El giro decolonial. Reflexiones para una diversidad epistémica más allá del capitalismo global. Bogotá: Siglo del Hombre Editores.

Castro-Gómez \& Mendieta, E. (1998). La translocalización discursiva de Latinoamérica en tiempos de globalización. En Castro-Gómez, C. \& Mendieta, E. Teorías sin disciplina (latinoamericanismo, poscolonialidad y globalización en debate). México: Miguel Ángel Porrúa Editores.

Classen, C. (1993). Worlds of sense. Exploring the senses in history and across cultures. London and New York: Routledge.

Córdoba, D.; Murillo P. \& Timarán A. (2015). Libro virtual Arqueología visual de los discos giratorios protopastos. Pasto: Editorial Institución Universitaria Cesmag.

Duch, LI. (1998). Mito, interpretación y cultura. Barcelona: Herder.

Duncan (1992). Arte en la tierra Nariño. En Silvia, A. Arte Precolombino y diseño en la cerámica Nariño. Bogotá: Presencia.

Estermann, J. (1998). Filosofía Andina. Estudio intercultural de la sabiduría autóctona andina. Quito: Ediciones Abya-Yala.

Gnecco, C. (2000). Memorias hegemónicas, memorias disidentes. El pasado como política de la historia. Santafé de Bogotá: Editorial Universidad del Cauca.

Gruzinski, S. (2003). La guerra de las imágenes. De Cristóbal Colón a Blade Runner (1492-2019). México D.F.: Fondo de Cultura Económica.

Lepe \& Granda (2006). Comunicación desde la periferia: tradiciones orales frente a la globalización. España: Ediciones Anthropos.

Mignolo, W. (2007). El pensamiento decolonial: desprendimiento y apertura. Un manifiesto. En El giro decolonial. Reflexiones para una diversidad epistémica más allá del capitalismo global. Bogotá: Siglo del Hombre Editores.

Mora, R. (2000). Abrir horizontes para la filosofía andina. Recuperado de http://lit.polylog.org/1/rmr-es.htm

Plazas, C. \& Echeverry (1982). Unos discos que giran. Revista Lámpara. 20 (87), 1- 8.

Rama A. (1987). La ciudad letrada. Hanover: NH. Ediciones del Norte.

Sepúlveda, J. (1996). Tratado sobre las justas causas de la guerra contra los indios. México: Fondo de Cultura Económica.

Uribe, M. (1989). Etnohistoria de las comunidades andinas prehispánicas del sur de Colombia. Anuario Colombiano de Historia Social y de la Cultura. 13-14. pp. 10-20.

Velásquez, A. \& Ramos, J. (2007). Patrones formales en las piezas de orfebrería precolombina de la cultura Tayrona. Universidad Eafit. 43. (145), 21-35. 